Working Memory, but Not IQ, Predicts Subsequent Learning in Children with Learning Difficulties

Tracy Packiam Alloway

European Journal of Psychological Assessment, Vol. 25, No.2, ๑2009, Hogrefe \& Huber Publishers

http://www. psycontent. com/content/1015-5759

This is the author's final, post-refereed version

Publisher required notice:

"This article does not exactly replicate the final version published in the journal European Journal of Psychological Assessment. It is not a copy of the original published article and is not suitable for citation." 


\title{
Working Memory, but Not IO, Predicts Subsequent Learning in Children with Learning Difficulties
}

\author{
Tracy Packiam Alloway \\ University of Durham, UK
}

\begin{abstract}
The purpose of the present study was to compare the predictive power of working memory and IQ in children identified as having learning difficulties. The term "working memory" refers to the capacity to store and manipulate information in mind for brief periods of time. Working-memory capacity is strongly related to learning abilities and academic progress, predicting current and subsequent scholastic attainment of children across the school years in both literacy and numeracy. Children aged between 7 and 11 years were tested at Time 1 on measures of working memory, IQ, and learning. They were then retested 2 years later on the learning measures. The findings indicated that working-memory capacity and domain-specific knowledge at Time 1, but not IQ, were significant predictors of learning at Time 2 . The implications for screening and intervention are discussed.
\end{abstract}

Keywords: working memory, IQ, reading, math, learning difficulties

\section{Introduction}

In the United Kingdom, any pupil who requires extra support to succeed in a mainstream classroom is classified as having special education needs (Department for Education and Skills, 2001). While the term "special educational needs" reflects a broad spectrum of problems, including physical or sensory difficulties, emotional and behavioral difficulties, or difficulties with speech, the focus in the present study is on children with general learning difficulties only. There is a strong empirical foundation for the view that learning difficulties reflect a fundamental deficit in working memory (Swanson \& Siegel, 2001). There is also well-documented evidence that general fluid intelligence is a good predictor of learning indices such as reading achievement (Stanovich, Cunningham, \& Freeman, 1984). The purpose of the present study was to compare the predictive power of working memory and IQ in children identified as having learning difficulties.

The term "working memory" refers to the capacity to store and manipulate information for brief periods of time. It provides a mental workspace that is used in many important activities in everyday life. Working memory is a relatively pure measure of a child's learning potential. As it is not strongly influenced by the child's prior experiences such as preschool education, or their socioeconomic background (e.g., maternal educational level), it tells us about a child's capacity to learn (Alloway, Gathercole, Adams et al., 2005; Dollaghan, Campbell, Needleman, \& Dunlosky, 1997; Weismer et al., 2000). In contrast, school-based assessments or even IQ tests measure knowledge that the child has already learned.

According to the Baddeley (2000) revision of the influential Baddeley and Hitch (1974) model, working memory consists of four components. The central executive is a domain-general component responsible for the control of attention and processing, which is involved in a range of regulatory functions including the retrieval of information from long-term memory (Baddeley, 1996). The temporary storage of information is mediated by two domain-specific stores: the phonological loop provides temporary storage of verbal material, and the visuo-spatial sketchpad is specialized for the maintenance and manipulation of visual and spatial representations (see Baddeley \& Logie, 1999, for a review). The fourth component, the episodic buffer, is responsible for binding information across informational domains and memory subsystems into integrated chunks. This model of working memory has been supported by evidence from studies of children (Alloway, Gathercole, \& Pickering, 2006; Alloway, Gathercole, Willis, \& Adams, 2004; Bayliss, Jarrold, Gunn, \& Baddeley, 2003; Gathercole, Pickering, Ambridge, \& Wearing, 2004), adult participants (Kane et al., 2004), neuropsychological patients, and neuroimaging research (Jonides, Lacey, \& Nee, 2005).

There is now extensive evidence that working-memory capacity, tapping the central executive in the model described above, constrains children's academic achievement. Studies have also reported close associations between working-memory capacity and pupils' performance on national assessments in literacy and numeracy (Alloway, Gathercole, Adams, et al., 2005; Gathercole \& Pick- 
ering, 2000; Gathercole, Pickering, Knight, \& Stegmann, 2004). Alloway, Gathercole, Willis, and Adams (2005) also found that children's working-memory impairments varied in severity according to level of special educational needs: Children with severe learning difficulties had greater working-memory impairments compared to those with mild learning difficulties (see also Pickering \& Gathercole, 2004). In contrast, their short-term memory performance was within age-expected levels.

Students with working-memory impairments struggle in the classroom because they are unable to hold in mind sufficient information to allow them to complete the task. Losing crucial information from working memory will cause them to forget many things: instructions they are attempting to follow, the details of what they are doing, where they have got to in a complicated task, and so on. Because those with working-memory impairments fail in many different activities on many occasions because of these kinds of forgetting, they will struggle to achieve normal rates of learning and so typically will make poor general academic progress (Alloway, Gathercole, Kirkwood, \& Elliott, 2007).

With respect to IQ and learning, there is a substantial literature demonstrating the correlation between IQ scores and educational success (see Kline, 1990). Given that the original intent of IQ tests was to determine an individual's ability to learn, this is expected. What is of interest in the present study is the predictive power of IQ in children with learning difficulties. Some researchers suggest that the link between these two factors is greatest when the individual is learning new information, rather than at later stages when it is suggested that gains made are the result of practice (see Jenson, 1980). A further issue of interest is the link between IQ and working memory in learning. Some researchers have suggested that the key factor underlying the relationship between working memory and learning is IQ (Nation, Adams, Bowyer-Crane, \& Snowling, 1999; Stothard \& Hulme, 1992). Although there is some evidence that working-memory capacity is dissociable from IQ (Alloway et al., 2004; Cain, Oakhill, \& Bryant, 2004; Gathercole, Alloway, Willis, \& Adams, 2006), it was important to test whether the two factors could be distinguished in terms of their predictive power in children with learning difficulties.

In the present study, children between 7 to 11 years were tested on measures of memory, IQ, reading, and math. They were then retested on reading and math 2 years later. All the participating children were identified by their school as having learning difficulties and were provided with additional assistance in school to support their learning needs. A key feature in the present study is that these children were selected based on learning failures in school. This meant that IQ standard scores were not restricted to less than 70 as is typical for studies on learning disabilities, and so provided a more robust comparison of the roles of working memory and IQ in predicting learning outcomes 2 years later. The present study explored the following hypothesis. If IQ does underlie the contribution of working memory to learning, then we would expect that working memory would not be a significant predictor of learning outcomes 2 years later, once the contribution of IQ was statistically controlled for. However, if working-memory capacity is dissociable from IQ, then we would expect that it would be a unique, significant predictor of reading and math performance.

\section{Method}

\section{Participants}

Children with learning difficulties were recruited from a larger study of 64 children, involving a wide range of cognitive measures (Alloway, Gathercole, Willis et al., 2005). At Time 1 (September 2002), all children were aged 7 to 11 years ( $M=9.0$ years; $S D=12.5$ months $)$ and were classified as having moderate learning difficulties sufficiently severe to warrant special educational support (Department for Education and Skills, 2001).

Of the original 64 children tested (September 2002; Time 1), 37 of these were retested on standardized tests of reading and math 2 years later (September 2004; Time 2). These children were aged 8 to 13 years $(M=10.8$ years; $S D=12.6$ months); there was a mean age difference of 23 months between testing times. There were 27 boys and 10 girls. None of these children had any physical, sensory, or behavioral impairments. Parental consent was obtained for all children participating in the study.

\section{Tasks - Procedure}

Each child was tested individually in a quiet area of the school for six sessions lasting up to $30 \mathrm{~min}$ per session across 5 to 6 weeks. The tests were administered in a fixed sequence designed to vary task demands across successive tests.

\section{Working Memory}

Memory tests from the Working Memory Test Battery for Children (WMTB-C; Pickering \& Gathercole, 2001) were administered at Time 1 only. The two verbal short-term memory measures (VSTM) that correspond to the phonological loop in the Baddeley working-memory model were the digit recall test and the word recall test. In each of these tests, the child hears a sequence of verbal items (digits and one-syllable words, respectively), and has to recall each sequence in the correct order. The three verbal workingmemory measures (VWM) associated with the central executive in the Baddeley working-memory model were the listening recall test, backward digit ecall test, and counting recall test. In the listening recall test, the child is presented with a series of spoken sentences, has to verify the sentence by stating "true" or "false," and recalls the final word for 
each sentence in sequence. In the backward digit recall test, the child is required to recall a sequence of spoken digits in the reverse order. In the counting recall test, the child is presented with a visual array of red circles and blue triangles. She or he is required to count the number of circles in an array and then recall the tallies of circles in the arrays that were presented. Two measures of the visuo-spatial short-term memory (VSSTM), that is, the block recall test and the visual patterns test, corresponding to the visuo-spatial sketchpad in the Baddeley working-memory model, were administered. In the block recall test, the child views nine cubes, randomly located on a board, and has to tap a set sequence in the correct order. In the visual patterns test (Della Sala, Gray, Baddeley, \& Wilson, 1997), the child views a two-dimensional grid of black and white squares for $3 \mathrm{~s}$, and has to mark the black squares on an empty grid. This test was normed for use with children (Pickering \& Gathercole, 2001).

\section{Intelligence}

A measure of intelligence, the Wechsler Intelligence Scale for Children - 3rd UK Edition (WISC-III; Wechsler, 1992) was also administered at Time 1 only. This test consists of five verbal (information, similarities, mathematics, vocabulary, and comprehension) and five performance measures (picture completion, coding, picture arrangement, block design, and object assembly). Composite standard scores for verbal IQ and performance IQ are reported.

\section{Learning Abilities}

Two standardized measures of learning abilities were administered at Time 1 and Time 2. The Wechsler Objective Reading Dimensions (WORD; Wechsler, 1993) consists of tests of basic reading, reading comprehension, and spelling for children. The Wechsler Objective Numerical Dimensions (WOND; Wechsler, 1996) assesses mathematical reasoning and number operations.

\section{Results}

Descriptive statistics for the 37 children at Times 1 and 2 are shown in Table 1. Composite memory scores were calculated

Table 1. Descriptive statistics of standard scores for the cognitive tests at Time 1 and Time 2

\begin{tabular}{|c|c|c|c|c|c|c|c|c|}
\hline \multirow[b]{2}{*}{ Measures } & \multicolumn{4}{|c|}{ Time 1} & \multicolumn{4}{|c|}{ Time 2} \\
\hline & Min & $\operatorname{Max}$ & $M$ & $S D$ & Min & $\operatorname{Max}$ & $M$ & $S D$ \\
\hline \multicolumn{9}{|l|}{ VSTM } \\
\hline Digit recall & 56 & 123 & 90.92 & 18.67 & & & & \\
\hline Word recall & 65 & 117 & 88.70 & 11.35 & & & & \\
\hline VSTM Composite & 61 & 119 & 89.81 & 13.03 & & & & \\
\hline \multicolumn{9}{|l|}{ VWM } \\
\hline Backward digit recall & 56 & 87 & 73.97 & 6.91 & & & & \\
\hline Counting recall & 55 & 98 & 71.41 & 11.80 & & & & \\
\hline Listening recall & 55 & 86 & 74.27 & 8.75 & & & & \\
\hline VWM Composite & 62 & 83 & 73.22 & 5.59 & & & & \\
\hline \multicolumn{9}{|l|}{ VSSTM } \\
\hline Block recall & 55 & 97 & 68.32 & 13.13 & & & & \\
\hline Visual patterns & 46 & 105 & 76.73 & 11.68 & & & & \\
\hline VSSTM Composite & 57 & 98 & 72.53 & 9.68 & & & & \\
\hline \multicolumn{9}{|l|}{ Intelligence } \\
\hline Verbal IQ & 61 & 108 & 83.51 & 11.86 & & & & \\
\hline Performance IQ & 62 & 110 & 79.84 & 12.12 & & & & \\
\hline \multicolumn{9}{|l|}{ Learning abilities } \\
\hline Basic reading & 63 & 106 & 83.97 & 10.07 & 61 & 112 & 85.14 & 12.06 \\
\hline Spelling & 64 & 111 & 85.76 & 10.57 & 60 & 106 & 82.16 & 11.69 \\
\hline Reading comprehension & 58 & 102 & 81.84 & 10.83 & 49 & 106 & 80.22 & 12.05 \\
\hline WORD Composite & 56 & 99 & 80.41 & 11.48 & 48 & 101 & 78.68 & 12.75 \\
\hline Math reasoning & 66 & 111 & 90.78 & 10.10 & 66 & 114 & 89.35 & 9.79 \\
\hline Numerical operations & 60 & 110 & 84.54 & 13.08 & 61 & 102 & 86.68 & 9.95 \\
\hline WOND Composite & 58 & 110 & 85.68 & 12.64 & 59 & 105 & 85.89 & 10.61 \\
\hline
\end{tabular}

Note: VSTM: Verbal short-term memory; VWM: verbal working memory; VSSTM: visuo-spatial short-term memory (VSSTM). 
Table 2. Correlations between all measures of short-term and working memory, IQ and learning at Time 1 and 2

\begin{tabular}{|c|c|c|c|c|c|c|c|c|c|}
\hline Measures & 1 & 2 & 3 & 4 & 5 & 6 & 7 & 8 & 9 \\
\hline \multicolumn{10}{|l|}{ Time 1} \\
\hline 1. VSTM & 1.00 & & & & & & & & \\
\hline 2. VWM & .26 & 1.00 & & & & & & & \\
\hline 3. VS STM & .05 & .31 & 1.00 & & & & & & \\
\hline 4. Verbal IQ & -.01 & $.42 * *$ & $.33 *$ & 1.00 & & & & & \\
\hline 5. Performance IQ & -.04 & $.49 * *$ & $.50^{* *}$ & $.65^{* *}$ & 1.00 & & & & \\
\hline 6. WORD composite & -.02 & .27 & -.06 & .22 & .17 & 1.00 & & & \\
\hline 7. WOND composite & .14 & $.58 * *$ & .30 & $.45^{* *}$ & $.55^{* *}$ & $.61 * *$ & 1.00 & & \\
\hline \multicolumn{10}{|l|}{ Time 2} \\
\hline 8. WORD composite & .04 & $.46^{* *}$ & -.04 & .26 & .16 & $.82 * *$ & $.58 * *$ & 1.00 & \\
\hline 9. WOND composite & .14 & $.71 * *$ & .30 & $.47 * *$ & $.50^{* *}$ & $.43 * *$ & $.81 * *$ & $.49 * *$ & 1.00 \\
\hline
\end{tabular}

Note: VSTM: Verbal short-term memory; VWM: verbal working memory; VSSTM: visuo-spatial short-term memory (VSSTM). *p<.05; **p $<.01$.

Table 3. Hierarchical regression analyses predicting reading skills

\begin{tabular}{|c|c|c|c|c|c|}
\hline & $R^{2}$ & $\Delta R^{2}$ & $\Delta F$ & $\beta$ & $T$ \\
\hline Variables & \multicolumn{5}{|c|}{ Model 1: Reading Time 2 (WORD) } \\
\hline Step 1: Verbal IQ & .069 & .069 & 1.26 & .080 & .673 \\
\hline Step 1: Performance IQ & .069 & .069 & 1.26 & -.164 & -1.345 \\
\hline Step 2: VWM & .233 & .180 & 2.47 & .301 & $2.895 * *$ \\
\hline \multirow[t]{2}{*}{ Step 3: Reading Time 1 (WORD) } & .753 & .527 & $70.44 * *$ & .754 & $8.204 * *$ \\
\hline & \multicolumn{5}{|c|}{ Model 2: Reading Time 2 (WORD) } \\
\hline Step 1: VWM & .207 & .207 & $9.12 * *$ & .301 & $2.895^{* *}$ \\
\hline Step 2: Reading Time 1 (WORD) & .739 & .532 & $69.20 * *$ & .754 & $8.204 * *$ \\
\hline Step 3: Verbal IQ & .753 & .014 & .91 & .080 & .673 \\
\hline \multirow[t]{2}{*}{ Step 3: Performance IQ } & .753 & .014 & .91 & -.164 & -1.345 \\
\hline & \multicolumn{5}{|c|}{ Model 3 Reading Time 2 (WORD) } \\
\hline Step 1: Reading Time 1 (WORD) & .679 & .679 & $73.96 * *$ & .754 & $8.204 * *$ \\
\hline Step 2: Verbal IQ & .688 & .009 & .48 & .080 & .673 \\
\hline Step 2: Performance IQ & .753 & .065 & .48 & -.164 & -1.345 \\
\hline Step 3: VWM & .753 & .065 & $8.38 * *$ & .301 & $2.895^{* *}$ \\
\hline
\end{tabular}

Note: VWM: verbal working memory; **p<.01.

Table 4. Hierarchical regression analyses predicting math skills

\begin{tabular}{|c|c|c|c|c|c|}
\hline & $R^{2}$ & $\Delta R^{2}$ & $\Delta F$ & $\beta$ & $T$ \\
\hline Variables & \multicolumn{5}{|c|}{ Model 1: Math Time 2 (WOND) } \\
\hline Step 1: Verbal IQ & .283 & .283 & $6.70 * *$ & .096 & .803 \\
\hline Step 1: Performance IQ & .283 & .283 & $6.70 * *$ & -.067 & -.524 \\
\hline Step 2: VWM & .547 & .264 & $19.25 * *$ & .358 & $3.164 * *$ \\
\hline \multirow[t]{2}{*}{ Step 3: Math Time 1 (WON) } & .748 & .201 & $25.43^{* *}$ & .596 & $5.043 * *$ \\
\hline & \multicolumn{5}{|c|}{ Model 2: Math Time 2 (WOND) } \\
\hline Step 1: VWM & .505 & .505 & $35.77 * *$ & .358 & $3.164 * *$ \\
\hline Step 2: Math Time 1 (WOND) & .742 & .237 & $31.27 * *$ & .596 & $5.043 * *$ \\
\hline Step 3: Verbal IQ & .748 & .005 & .33 & .096 & .803 \\
\hline \multirow[t]{2}{*}{ Step 3: Performance IQ } & .748 & .005 & .33 & -.067 & -.524 \\
\hline & \multicolumn{5}{|c|}{ Model 3: Math Time 2 (WOND) } \\
\hline Step 1: Math Time 1 (WOND) & .654 & .654 & $66.23 * *$ & .596 & $5.043 * *$ \\
\hline Step 2: Verbal IQ & .669 & .014 & .72 & .096 & .803 \\
\hline Step 2: Performance IQ & .669 & .014 & .72 & -.067 & -.524 \\
\hline Step 3: VWM & .748 & .079 & $10.01 * *$ & .358 & $3.164 * *$ \\
\hline
\end{tabular}


by averaging the standard scores of the individual tests associated with each memory component on the basis of the close relationship among these measures in typically-developing populations (Alloway et al., 2006). There were three composite scores: (a) VSTM, (b) VWM, and (c) VSSTM.

Looking first at performance on the memory measures at Time 1, the data indicate that the mean scores fell within one standard deviation of the mean (i.e., 15 points from the norm of 100) in measures of VSTM. Performance levels in measures of the VWM and VSSTM were considerably lower, with mean scores almost two standard deviations from the mean in some cases (e.g., counting recall and block recall, 71.41 and 68.32, respectively). It is worth noting that the majority of this sample achieved standard scores of less than 86 in the two working-memory measures used to screen children for memory impairments in a largescale study of children with memory impairments (Alloway, Gathercole et al., 2007): backward digit recall, 96\%; and listening recall, 87\%. Mean IQ scores were also below age-expected levels: 83.51 and 79.84 for verbal IQ and performance IQ, respectively.

Mean scores on the learning measures also fell one standard deviation from the standardized mean at Time 1 (with the exception of the mathematical reasoning subtest from the WOND). At Time 2, there was a similar pattern of performance in the learning measures: Mean scores fell below age-expected levels. In order to compare performance in learning between Times 1 and 2, paired sample $t$ tests were performed on standard scores for all learning subtests and composite scores ([Cronbach's???] $\alpha$ level adjusted to .007 for multiple comparisons). In the reading test, there was no significant difference in the following subtests: basic reading, $t<1$; reading comprehension, $t<$ 1 , WORD composite, $t(36)=1.44, p=.16$; however, spelling scores were significantly worse at Time $2, t(36)=3.26$, $p=.002$, Cohen's $d=.32$. In the math test, there was no significant difference in performance across all subtests: mathematical reasoning, $t(36)=1.86, p=.07$; numerical operations, $t<1$; WOND composite, $t<1$.

Correlations between memory composite scores, IQ, and learning composites at Time 1 and 2 were conducted using the standard scores (see Table 2). The relationship between VWM, VSSTM, and IQ was significant, with $r$ ranging from .33 to .50 . With respect to memory measures and learning, only VWM was significantly associated with reading and math at both testing times, with the exception of reading at Time 1 ( $r$ ranging from .46 to .71). Finally, IQ was only significantly related to math at both testing times ( $r$ ranging from .45 to .55 ).

To investigate the relationship between VWM, IQ, and learning at Time 1 and 2, a series of hierarchical regression analyses were performed with sets of predictor variables entered for each of two learning variables: composite reading standard scores (WORD) and composite math standard scores (WOND). The goal of these analyses was to explore which particular cognitive abilities shared unique variance with the two measures of learning abilities. As only VWM was significantly associated with learning outcomes (see Table 2), VSTM and VSSTM were not included in the following analyses. Verbal IQ and performance IQ were always entered together in the analyses. Three models for each dependent variable were tested and are shown in Table 3 and Table 4 for reading and math, respectively. Standardized $\beta$ values and $t$ statistics are also listed. In Model 1 , the verbal IQ and performance IQ standard scores were entered together at the first step, the VWM composite score was the second step, and the WORD composite at Time 1 was the final step, with reading at Time 2 as the outcome measure. The additional variance linked with verbal working memory and reading skills at Time 1 was significant ( $16.3 \%$ and $52 \%$, respectively). In Model 2, VWM was entered first, followed by reading skills at Time 1, and finally IQ. The variance accounted for by VWM (20.7\%) and by reading skills at Time $1(53.2 \%)$ were both significant predictors of reading skills 2 years later. However, verbal and performance IQ did not account for any additional significant variance. In Model 3, reading skills at Time 1 was entered first, followed by IQ, and VWM as the final step. Reading skills at Time 1 (67.9\%) and VWM (6.5\%) both accounted for a significant proportion of variance associated with reading skills at Time 2 .

Looking next at math skills (Table 4), the pattern of findings is similar. In Model 1, the variance associated with IQ $(28.3 \%)$, VWM (26.4\%), and math skills as the final step at Time $1(20.1 \%)$ were all significant predictors of math skills 2 years later. In Model 2, the variance accounted by verbal working memory $(50.5 \%)$ and math skills at Time 1 $(23.7 \%)$ were both significant predictors of math skills 2 years later. However, verbal and performance IQ did not account for any significant additional variance. In Model 3 , math skills at Time $1(65.4 \%)$ and VWM entered as the final step (7.9\%) accounted for a significant proportion of variance associated with math skills at Time 2 . In summary, it appears that both VWM capacity and prior learning uniquely predicted outcomes in reading and math 2 years later.

\section{Discussion}

The aim of the present study was to investigate the predictive power of working memory and IQ in reading and math skills in children with learning difficulties. The findings from the regression analyses indicate that both working-memory capacity and prior domain-specific knowledge were unique predictors of learning outcomes 2 years later. The finding that initial reading and math skills were important precursors to subsequent learning fits well with the existing literature (see Swanson, 2006; and Butterworth, 2005, for reviews in reading and math, respectively). IQ was not a significant predictor of learning outcomes once working-memory capacity and prior knowledge were statistically accounted for.

With respect to the contribution of working memory to 
learning, this suggests that working memory is not simply a proxy for IQ, but rather shares unique links with learning. This is in line with findings from cross-sectional studies indicating that the specificity of associations between working memory and achievement persist after differences in IQ have been statistically controlled in children with learning difficulties (Gathercole, Alloway et al., 2006; see also Nation et al., 1999; Stothard \& Hulme, 1992; Swanson \& Saez, 2003). Further evidence that verbal working-memory taps more than general ability is provided by reports of differences in working-memory scores in children with reading comprehension problems and other learning disabilities even after verbal IQ has been accounted for (Cain et al., 2004; Siegel \& Ryan, 1989).

It is also of interest that working-memory capacity predicted subsequent skills in both reading and math. This corresponds with research that working-memory impairments are associated with pervasive learning deficits that extend beyond reading or math alone. For example, Pickering and Gathercole (2004) found that children classified by their schools as having problems in both reading and mathematics had depressed performance on working-memory tasks, but that individuals with difficulties restricted to reading did not (see also Wagner \& Muse, 2006). The finding that short-term memory capacity was not significantly associated with learning is in line with the suggestion that the strongest link between this and learning is during the formative years of reading between the ages of four to six years and diminishes thereafter (see Alloway, Gathercole, Willis et al., 2005). It is also consistent with previous research showing that short-term memory deficits alone are generally not associated with substantial failures in educational progress (Gathercole, Pickering, Knight et al., 2004).

The present study confirms that working-memory capacity underpins subsequent learning failures and establishes the value of targeted intervention to minimize such failures. The first crucial step in supporting children with working-memory impairments is proper diagnosis. However, at present, working-memory problems often go undetected in children or are misdiagnosed as attentional problems (Gathercole, Lamont, \& Alloway, 2006). One useful tool to identify and support children with working memory impairments is the Automated Working Memory Assessment (AWMA; Alloway, 2007). It is the first standardized tool for nonspecialist assessors such as classroom teachers to screen their pupils for significant working-memory problems quickly and effectively.

The likelihood that children with poor working-memory capacity will face academic problems in school was recently investigated using the AWMA (Alloway, Gathercole et al., 2007). In a large-scale screening study of over 3000 children aged 5 and 10 years, $10 \%$ of children in a mainstream classroom were diagnosed with working-memory impairments. Inspection of their learning profiles indicated that $67 \%$ achieved standard scores of less than 86 in reading (WORD, Weschler, 1993) and 70\% in math (WOND, Weschler, 1996). This suggests that working-memory impairments are associ- ated with low learning outcomes. The AWMA is also a valuable tool in working with atypical populations, such as those with dyslexia, specific language impairment, developmental coordination disorder, [please define]ADHD, and autistic spectrum disorder. The specificity of the diagnosis identifies not only areas of deficit, but also areas of strength on which compensatory strategies can be effectively built (Alloway, Rajendran, Archibald, \& Pickering, 2007).

One explanation for why children with working-memory impairments perform poorly could be because many classroom activities place heavy demands on working memory. These children often struggle to meet the working-memory demands of individual learning episodes and as a result fail to acquire the knowledge and skills necessary for competence in key academic domains such as reading and math (Gathercole, Lamont et al., 2006). A targeted intervention that focuses on supporting working memory in learning may be essential to minimize the adverse consequences of poor working-memory capacity on academic learning. Effective classroom management techniques for reducing working-memory loads in key learning activities include simplifying complex tasks and repeating task instructions. In addition, facilitating the child's use of strategies can prevent working-memory overload (see Gathercole \& Alloway, 2008, for further details).

\section{Acknowledgments}

This research was supported by a British Academy Research Grant awarded to the author. I would like to thank Anastasia Efklides and Ross Alloway for helpful comments on an earlier version of this manuscript.

\section{References}

Alloway, T.P. (2007). Automated working memory assessment. London: Harcourt Assessment.

Alloway, T.P., Gathercole, S.E., Adams, A.M., Willis, C., Eaglen, R., \& Lamont, E. (2005). Working memory and other cognitive skills as predictors of progress toward early learning goals at school entry. British Journal of Developmental Psychology, 23, 417-426.

Alloway, T.P., Gathercole, S. E, Kirkwood, H.J., \& Elliott, J.E. (2007). The cognitive and behavioral characteristics of children with low working memory. Manuscript submitted for publication.

Alloway, T.P., Gathercole, S.E., \& Pickering, S.J. (2006). Verbal and visuo-spatial short-term and working memory in children: Are they separable? Child Development, 77, 1698-1716.

Alloway, T.P., Gathercole, S.E., Willis, C., \& Adams, A.M. (2004). A structural analysis of working memory and related cognitive skills in early childhood. Journal of Experimental Child Psychology, 87, 85-106.

Alloway, T.P., Gathercole, S.E., Willis, C., \& Adams, A.M. (2005). Working memory and special educational needs. Educational and Child Psychology, 22, 56-67. 
Alloway, T.P., Rajendran, G., Archibald, L.M., \& Pickering, S. (2007). Working memory profiles of atypical children. Manuscript submitted for publication.

Baddeley, A.D. (1996). Exploring the central executive. Quarterly Journal of Experimental Psychology, 49A, 5-28.

Baddeley, A.D. (2000). The episodic buffer: A new component of working memory? Trends in Cognitive Sciences, 4, 417-423.

Baddeley A.D., \& Hitch G. (1974). Working memory. In G. Bower (Ed.), The psychology of learning and motivation (Vol. 8, pp. 47-90). New York: Academic.

Baddeley, A.D., \& Logie, R.H. (1999). Working memory: The multiple-component model. In A. Miyake \& P. Shah (Eds.), Models of working memory: Mechanisms of active maintenance and executive control (pp. 28-61). New York: Cambridge University Press.

Bayliss, D.M., Jarrold, C., Gunn, D.M., \& Baddeley, A.D. (2003). The complexities of complex span: Explaining individual differences in working memory in children and adults. Journal of Experimental Psychology: General, 132, 71-92.

Butterworth, B. (2005). The development of arithmetical abilities. Journal of Child Psychology and Psychiatry, 46, 3-18.

Cain, K., Oakhill, J., \& Bryant, P. (2004). Children's reading comprehension ability: Concurrent prediction by working memory, verbal ability, and component skills. Journal of Educational Psychology, 96, 31-42.

[not cited in text]Case, R., Kurland, D.M., \& Goldberg, J. (1982). Working memory capacity as long-term activation: An individual differences approach. Journal of Experimental Psychology: Learning, Memory, and Cognition, 19, 1101-1114.

Della Sala, S., Gray, S., Baddeley, A.D., \& Wilson, L. (1997). Visual Patterns Test. London: Harcourt Assessment.

Department for Education and Skills. (2001). Special educational needs - A guide for parents and carers. London: Department for Education and Employment.

Dollaghan, C., Campbell, T., Needleman, H., \& Dunlosky, G. (1997). Reducing bias in language assessment: A processing-dependent measure. Journal of Speech, Language, and Hearing Research, 40, 519-525.

Gathercole, S.E., \& Alloway, T.P. (2008). Working memory and learning: A practical guide. London: Sage.

Gathercole, S.E., Alloway, T.P., Willis, C.S., \& Adams, A.M. (2006). Working memory in children with reading disabilities. Journal of Experimental Child Psychology, 93, 265-281.

Gathercole, S.E., Lamont, E., \& Alloway, T.P. (2006). Working memory in the classroom. In S. Pickering (Ed.), Working memory and education (pp. 219-240). Oxford, UK: Elsevier.

Gathercole, S.E., \& Pickering, S.J. (2000). Assessment of working memory in 6- and 7-year-old children. Journal of Educational Psychology, 92, 377-390.

Gathercole, S.E., Pickering, S.J., Ambridge, B., \& Wearing, H. (2004). The structure of working memory from 4 to 15 years of age. Developmental Psychology, 40, 177-190.

Gathercole, S.E., Pickering, S.J., Knight, C., \& Stegmann, Z. (2004). Working memory skills and educational attainment: Evidence from National Curriculum assessments at 7 and 15 years of age. Applied Cognitive Psychology, 18, 1-16.

Jensen, A.R. (1980). Bias in mental testing. New York: Free Press.

Jonides, J., Lacey, S.C., \& Nee, D.E. (2005). Processes of working memory in mind and brain. Current Directions in Psychological Science, 14, 2-5.

Kane, M.J., Hambrick, D.Z., Tuholski, S.W., Wilhelm, O., Payne,
T.W., \& Engle, R.W. (2004). The generality of working-memory capacity: A latent-variable approach to verbal and visuo-spatial memory span and reasoning. Journal of Experimental Psychology: General, 133, 189-217.

Kline, P. (1990). Intelligence: The psychometric view. London: Routledge.

Nation, K., Adams, J.W., Bowyer-Crane, C.A., \& Snowling, M.J. (1999). Journal of Experimental Child Psychology, 73, 139-158.

Pickering, S.J., \& Gathercole, S.E. (2001). Working memory test battery for children. London: Harcourt Assessment.

Pickering, S.J., \& Gathercole, S.E. (2004). Distinctive working memory profiles in children with special educational needs. $E d-$ ucational Psychology, 24, 393-408.

Siegel, L.S., \& Ryan, E.B. (1989). The development of working memory in normally achieving and subtypes of learning disabled children. Child Development, 60, 973-980.

Stanovich, K.E., Cunningham, A.E., \& Freeman, D.J. (1984). Intelligence, cognitive skills, and early reading progress. Reading $R e$ search Quarterly, 19, 278-303.

Stothard, S.E., \& Hulme, C. (1992). Reading comprehension difficulties in children. Reading and Writing: An Interdisciplinary Journal, 4, 245-256.

Swanson, H.L. (2006). Working memory and reading disabilities: Both phonological and executive processing deficits are important. In T.P. Alloway \& S.E. Gathercole (Eds.), Working memory in neurodevelopmental conditions (pp. 59-88). East Sussex, UK: Psychology Press.

Swanson, H.L., \& Saez, L. (2003). Memory difficulties in children and adults with learning disabilities. In H.L. Swanson, S. Graham, \& K.R. Harris (Eds.), Handbook of learning disabilities (pp. 182-198). New York: Guildford.

Swanson, H.L., \& Siegel, L. (2001). Learning disabilities as a working memory deficit. Issues in Education: Contributions from Educational Psychology, 7, 1-48.

Wagner, R.K., \& Muse, A. (2006). Working memory deficits in developmental dyslexia. In T.P. Alloway \& S.E. Gathercole (Eds.), Working memory in neurodevelopmental conditions (pp. 41-58). East Sussex, UK: Psychology Press.

Wechsler, D. (1992). Wechsler Intelligence Scale for Children third edition UK. London: Harcourt Assessment.

Wechsler, D. (1993). Wechsler Objective Reading Dimensions. London: Harcourt Assessment.

Wechsler, D. (1996). Wechsler Objective Numerical Dimensions. London: Harcourt Assessment.

Weismer, S.E., Tomblin, J.B., Zhang, X., Buckwalter, P., Chynoweth, J.G., \& Jones, M. (2000). Nonword repetition performance in school-age children with and without language impairment. Journal of Speech, Language, and Hearing Research, 43, 865-878.

Tracy Packiam Alloway

School of Education

University of Durham

Leazes Road

Durham DH1 1TA

UK

Tel. +441913348330

E-mail t.p.alloway@durham.ac.uk 